\title{
Effects of metoprolol on epinephrine-induced takotsubo-like left ventricular dysfunction in non-human primates
}

\author{
Yasukatsu Izumi $^{1,4}$, Hideaki Okatani ${ }^{2,4}$, Masayuki Shiota ${ }^{1}$, Takafumi Nakao ${ }^{1}$, Ryota Ise $^{2}$, Go Kito ${ }^{1}$, \\ Katsuyuki Miura ${ }^{3}$ and Hiroshi Iwao ${ }^{1}$
}

Takotsubo cardiomyopathy, alternatively known as stress cardiomyopathy, is an increasingly recognized clinical syndrome characterized by acute reversible apical ventricular dysfunction. To elucidate the mechanism, we tried to make a new model of takotsubo-like cardiomyopathy in non-human primates. Echocardiography revealed that repeated intravenous infusion of epinephrine overdose in cynomolgus monkeys induced takotsubo-like cardiomyopathy, which is characterized by progressive left ventricle and depressed systolic function with severe hypokinesis in apical regions and hyperkinesis in the basal region. Although this cardiac dysfunction almost normalized after a month even without any treatment, metoprolol, a $\beta$-blocker, improved the decreased ejection fraction earlier than in the control. Luxol fast blue staining, which is useful for estimating myocytolysis, showed that increased myocytolysis was observed in the apical ventricle of the epinephrine-infused heart. Metoprolol diminished epinephrine-induced cardiomyocytolysis. To explain the mechanism of takotsubo myopathy and the effect of metoprolol, gene expressions in apical or basal ventricle were compared. Heart failure-related genes, such as brain natriuretic peptide, connective tissue growth factor and osteopontin; calcium signaling-related genes, such as ryanodine receptor 2 , sarcoendoplasmic reticulum $\mathrm{Ca}^{2+}$-ATPase $2 \mathrm{~A} 2$ and adenylate cyclase 7 ; renin-angiotensin system-related genes, such as angiotensinogen, angiotensin II receptor, type 1 and type 2; and mitochondria-related genes, such as peroxisome proliferatoractivated receptor- $\gamma$ co-activator- $1 \alpha$, cytochrome $c$ and transcription factor A mitochondrial, were significantly changed at the apical ventricle rather than at the basal ventricle. The changes of some genes improved with metoprolol treatment. These results indicate that this model is valuable in understanding the pathogenesis of takotsubo cardiomyopathy and the effectivity of $\beta$-blockers. Hypertension Research (2009) 32, 339-346; doi:10.1038/hr.2009.28; published online 20 March 2009

Keywords: $\beta$-adorenoceptor; epinephrine; echocardiography; takotsubo cardiomyopathy

\section{INTRODUCTION}

A new cardiac disease characterized by extensive akinesia with ballooning, without significant coronary artery lesion, has recently been reported. ${ }^{1-6}$ Clinically, it is characterized by acute onset of chest pain and is associated with ECG changes such as ST elevation, ST depression or deep T-wave inversion. It has been named takotsubo cardiomyopathy because of the shape taken by the left ventricle. The following triggering factors were observed: sudden psychological or physical stress, ${ }^{1,7-9}$ severe physiological and emotional stress in a setting of a large catastrophic event such as an earthquake ${ }^{10}$ and accidental iatrogenic epinephrine overdose. ${ }^{11,12}$ Although all these cases revealed transient left ventricular (LV) dysfunction with severe chest pain and ECG changes that precipitate in acute myocardial infarction, LV function recovered within 2-4 weeks of presentation. Nevertheless, the pathophysiological mechanism underlying the transient LV apical ballooning is unclear.
Interestingly, there have been several reports about the relationship between takotsubo cardiomyopathy and hypertension. For example, a takotsubo-like cardiomyopathy has been associated with a pheochromocytoma which is one of the causes of secondary hypertension. ${ }^{13,14}$ Ionescu reported a case of takotsubo cardiomyaopathy in a female patient with a history of poorly controlled hypertension. ${ }^{15}$ She had dynamic obstruction of the outflow tract and moderate secondary mitral regurgitation. Furthermore, patients without myocardial ischemia developed LV apical or basal akinesis as a result of hypertensive response during exercise stress. ${ }^{16}$ These reports suggest that takotsubo cardiomyopathy can be one of the potential causes of secondary hypertension.

Cardiotoxic effects of excessive catecholamine blood level have been documented for several decades in experimental models and in the human heart. ${ }^{17-19}$ It is known that excessive doses of catecholamines

${ }^{1}$ Department of Pharmacology, Osaka City University Medical School, Osaka, Japan; ${ }^{2}$ Drug Safty Research Laboratories, Shin Nippon Biomedical Laboratories Ltd, Kagoshima, Japan and ${ }^{3}$ Applied Pharmacology and Therapeutics, Osaka City University Medical School, Osaka, Japan

4These authors contributed equally to this work.

Correspondence: Dr Y Izumi, Department of Pharmacology, Osaka City University Medical School, 1-4-3 Asahimachi, Abeno-ku, Osaka 545-8585, Japan.

E-mail: izumi@msic.med.osaka-cu.ac.jp

Received 4 December 2008; revised 19 January 2009; accepted 22 January 2009; published online 20 March 2009 
produce diffuse myocardial destruction with myocyte loss and necrosis, as well as extensive fibrosis. Rat, ${ }^{20}$ rabbit $^{21}$ and canine ${ }^{22}$ have been used as experimental models of heart failure using excessive dosing of catecholamine. However, earlier high-dose catecholamine infusion models are used to investigate the mechanism of chronic or acute heart failure. Various mechanisms of epinephrine-induced cardiotoxicity have been postulated to be involved in the pathogenesis of cardiomyopathy. Catecholamine-induced myocardial cell damage and fibrosis result from a reduction in intracellular glutathione level with an accumulation of reactive oxygen radicals. ${ }^{23}$ Catecholamineinduced coronary vasoconstriction with radical generation resulting from ischemia produces characteristic myocardial lesions that include focal myofiber necrosis and degeneration and mononuclear leukocytic infiltration. ${ }^{18,19}$ Catecholamine-induced increase in myocardial $\mathrm{Ca}^{2+}$ content results in over-stimulation of myofilaments, increase in contractile force and oxygen requirement, as well as excessive ATP breakdown, contributing to cardiac muscle cell injury. However, an impaired cardiac performance in many animal models is irreversible.

Recently, we reported that real-time three-dimensional echocardiography provides not only the three-dimensional LV shape in motion but also accurately estimates LV volume and function in cynomolgus monkeys. ${ }^{24,25}$ Our preliminary data have shown that the acute effect of excess epinephrine-induced LV dysfunction in cynomolgus monkeys can be measured using echocardiographic parameters, and this model has the characteristic syndrome, namely, extensive akinesia of the apical and mid portions of the left ventricle. Accordingly, the main purpose of this study is to determine if acutely excessive epinephrine in a non-human primate is associated with takotsubo-like LV dysfunction. Furthermore, to address the therapy of LV dysfunction in this model, metoprolol, a $\beta$-blocker, was administered.

\section{METHODS}

\section{Animals}

All procedures involving animals were approved by the animal care and use committee of Shin Nippon Biomedical Laboratories and Osaka City University, and were performed in accordance with standards published by the National Research Council (Guide for the Care and Use of Laboratory Animals, NIH OACU) and the National Institutes of Health Policy on Human Care and Use of Laboratory Animals.

Male cynomolgus monkeys (Macaca fascicularis, purpose-bred) aged 4-6 years, originally imported from China, were used in this study. After a 1-month international quarantine, the animals were acclimated to the test facility's stock colony until use. The monkeys were housed singly in stainless-steeled cages $63 \mathrm{~cm}$ wide by $76 \mathrm{~cm}$ high by $76 \mathrm{~cm}$ deep (conforming to NIH requirements) in a test room maintained at a temperature of $26 \pm 2{ }^{\circ} \mathrm{C}$ and $50 \pm 10 \%$ humidity with artificial lighting from 0600 to 1800 hours and with air changes 10 times per hour. The animals were fed Teklad Global 25\% Protein Primate Diet (Harlan Sprague Dawley Inc., Indianapolis, IN, USA) and water (on-site well) was provided ad libitum. On the day of the experiments, the animals weighed between 4.0 and $6.0 \mathrm{~kg}$.

\section{Experimental protocol}

On the day of experiment, the animals were anesthetized with inhalation of isoflurane (Abbott Laboratories, Abbott Park, IL, USA), and orotracheal intubation was performed without any muscle relaxant using a $3.0 \mathrm{~mm}$ endotracheal tube (107-030, Mallinckrodt Medical Ltd, Hazelwood, MO, USA). The animals were maintained under anesthesia with $1.0 \%$ isoflurane and mechanically ventilated through an endotracheal tube. The animals were placed in the left lateral position, and heart rate was maintained at $130 \pm 10$ b.p.m. for real-time three-dimensional echocardiographic measurement. The opened circuit anesthetic system was supplied with a fresh gas flow of $31 \mathrm{~min}^{-1}$ of $20-40 \%$ oxygen monitored at the common gas outlet and the balance of nitrogen. Body temperature was kept between 36.5 and $38.0^{\circ} \mathrm{C}$ by use of a water flow warming system (MICROTEMP II, Japan Medical Dynamic Marketing Inc., Tokyo, Japan).

Echocardiographic (real-time three-dimensional) measurements were performed, as described earlier. ${ }^{24,25}$ Baseline measurements of all the animals were performed, and epinephrine (Sigma, St Louis, MO, USA) was infused intravenously. Acute cardiomyopathy, namely, acute LV dysfunction, was induced in 25 cynomolgus monkeys by two repetitive epinephrine infusions at a rate of $10 \mu \mathrm{g} \mathrm{kg}^{-1} \mathrm{~min}^{-1}$. However, after measuring the echocardiographic parameters on day 3 , animals with an ejection fraction (EF) value less than 40 were selected as the acute cardiomyopathy model animals.

In the first experiment, cardiomyopathy monkeys were randomly divided into two groups as follows: saline group $(n=6)$ or metoprolol group $(n=4)$. After measuring the baseline values of echocardiographic parameters in each animal, saline or metoprolol $\left(0.3 \mathrm{mg} \mathrm{kg}^{-1} \mathrm{~min}^{-1}\right)$ was infused intravenously for $10 \mathrm{~min}$. The parameters were recorded $10 \mathrm{~min}$ after starting the infusion, and 30 and $120 \mathrm{~min}$, and 1, 10 and 30 days after the end of infusion. For intravenous administration, metoprolol was dissolved in saline.

In the second experiment, the cardiomyopathy monkeys were killed on day 1 after saline $(n=5)$ or metoprolol $(n=4)$ infusion for histological evaluation and RNA analysis. Normal monkeys without epinephrine $(n=5)$ were used as control.

\section{Assessment of LV function in real-time three-dimensional echocardiography}

Acquisition of one full volume took 5-8 s. The pyramidal data set obtained from the apical four-chamber view contained the whole heart structure. Data analysis was performed using the Tom Tec 4D Cardio-View RT. Eight longitudinal levels at intervals of $45^{\circ}$ were selected around this rotation axis. After planimetering the eight levels, LV volume (end-diastolic value and end-systolic value) was calculated using the measuring algorithm. A number of parameters were then calculated.

\section{Histological evaluation}

Tissue slices from each heart were embedded in paraffin. To determine myocytolysis in myocardial tissue, Luxol fast blue staining (Kluver-Barrera's stain) was performed, as described earlier. ${ }^{26}$ Deparaffinized and hydrated sections were stained for $24 \mathrm{~h}$ with the Luxol fast blue solution $(0.1 \%$ Solvent Blue $38,0.5 \%$ acetic acid in alcohol) at a $58{ }^{\circ} \mathrm{C}$. Differentiation was performed with $0.05 \%$ lithium carbonate solution for $15 \mathrm{~s}$ and with $70 \%$ ethanol for $3 \mathrm{~min}$. After differentiation, the tissues were stained in a cresyl violet solution for $7 \mathrm{~min}$ at $37^{\circ} \mathrm{C}$ and were then dehydrated.

\section{RNA analysis}

RNA from the basal and apical portions of the left ventricles was isolated using ISOGEN (Nippon Gene, Toyama, Japan) and purified with the RNeasy Fibrous Tissue Kit (Qiagen, Germantown, MD, USA). To elucidate the gene expression levels, we subjected the RNA samples to quantitative real-time RT-PCR (ABI Prism 7700, Perkin Elmer Applied Biosystems, Foster City, CA, USA). One-step quantitative real-time reverse transcriptase-PCR reactions were performed using $100 \mathrm{ng}$ of total RNA per reaction. TaqMan primers and probes were designed using Primer 3 (v. 0.4.0); see Table 1. For normalization, transcript levels were compared with glyceraldehyde-3-phosphate dehydrogenase.

\section{Statistical analysis}

All data are presented as mean \pm s.e.m. Comparisons among the groups were made by one-way analysis of variance. For differences between two groups, Student's $t$-test was used when appropriate. Differences were considered statistically significant at a value of $P<0.05$.

\section{RESULTS}

\section{Acute experimental cardiomyopathy}

Nine of the 25 cynomolgus monkeys died suddenly during or shortly after the first or second epinephrine infusion. In the ECG, ventricular fibrillation was induced after bundle branch type premature ventricular contraction, tachycardia (VT) and polymorphic VT after the end 
Table 1 Sequences of the quantitative reverse transcription-PCR probes and primers used in this study

\begin{tabular}{|c|c|c|c|}
\hline Symbol & Forward primer & Probe & Reverse primer \\
\hline Gapd & GTATGACAACAGCCTCAAGATC & ACCACCAACTGCTTAGCACC & TGTGGTCATGAGTCCTTCCA \\
\hline Nppb & CACCGCAAAATGGTCCT & AGGGTCTGGCTGCTTTGG & GATCCGGTCCATCTTCCTC \\
\hline Spp1 & CAGTTAAACAGGCTGATTCTGG & TCTGAGGAAAAGCAGCTTTACA & GGCCACAGCATCTGGGTAT \\
\hline Ryr2 & TGTATCTGTGCTGCCTGTCC & CCTCCCGGTCTTCAACTGAT & CTCTTGCAAGCCAACATCAA \\
\hline Serca2 & TCTGGGTCAATCTGGTGACA & CTGCCTGCCACTGCACTG & GTCCAGATCAGGAGGGTTGA \\
\hline Agtr1 & ACGTGTCTCAGCATTGATCG & ACCTGGCTATTGTTCACCCA & TGCAGGTGACTTTGGCTACA \\
\hline Agtr2 & ACCAACAGCTGCGTTAATCC & TGTTTTGTTGGAAACCGGTT & AAACACACTGCGGAGCTTCT \\
\hline Ppargcla & CCTTGCAGCACAAGAAAACA & CTGAACAAGCACTTCGGTCA & TGCTTCGTCGTCAAAAACAG \\
\hline Cycs & AGACTGGGCCAAATCTCCAT & GTCAGGCCCCTGGATACTCT & GTTCTTATTGGCGGCTGTGT \\
\hline Tfam & TGGAATTTGAAACACTTTGCAT & GACAGCCAACTATGGCCTG & GTCATACAAAGCAGGCAGCA \\
\hline Adrab2 & GAGCACAAAGCCCTCAAGAC & GCTGCCCTTCTTCATCGTTA & TCCTGGATCACATGCACAAT \\
\hline
\end{tabular}

a

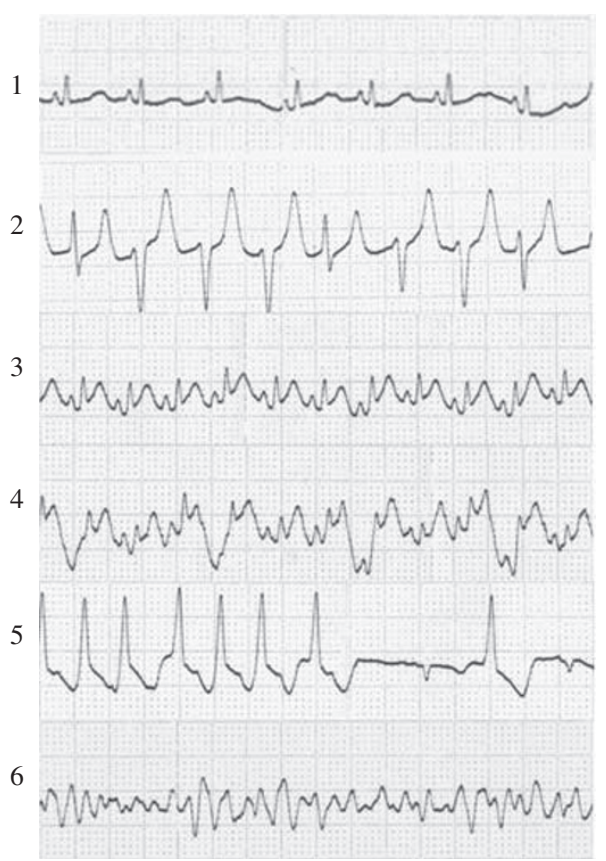

b
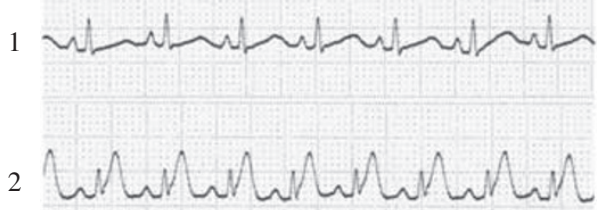

3

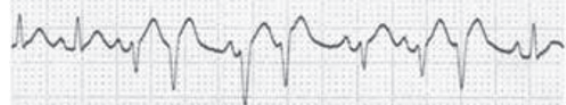

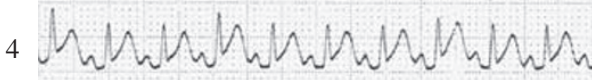
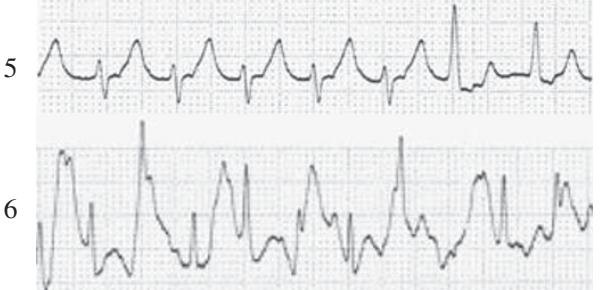

Figure 1 Changes in typical ECG in dead monkey (a) and that with takotsubo-like cardiomyopathy (b) after epinephrine infusion. 1: ECG before epinephrine infusion, 2-6: each ECG shows wave patterns observed during epinephrine infusion. ${ }^{2-6}$

of the first epinephrine infusion (Figure 1). Suddenly, massive hemorrhage through tracheal cannula was observed in all monkeys that died, and pulmonary edema and pulmonary hemorrhage were found at autopsy.

Effects of metoprolol on acute experimental cardiomyopathy Echocardiographic examinations showed that infusion of epinephrine induced cardiomyopathy $(\mathrm{EF}<40 \%)$ with takotsubo-like apical akinesia, a form of LV systolic dysfunction characterized by extensive apical akinesia with normal or hypercontractile baseline segments in a three-dimensional echocardiogram. Epinephrine infusion produced a marked increase in systolic and diastolic pressures with transient reflex bradycardia immediately after starting the infusion. However, heart rate increased severely thereafter, and tachycardia lasted throughout the epinephrine infusion (Figure 2a). Changes in blood pressure and heart rate during the second epinephrine infusion were similar to those seen during the first infusion (Figure 2b).

Figure 3 shows the time course of EF. Metoprolol significantly improved LV dysfunction, including the decreased EF and abnormal wall motion of the apical portion, at $10 \mathrm{~min}(40.5 \pm 1.3 \%)$ and $24 \mathrm{~h}$ after the end of infusion. Although metoprolol tended to show improvement in EF from 10 to 30 days after the end of infusion, cardiac dysfunction by the epinephrine injection almost normalized after a month even without any treatment. 
a

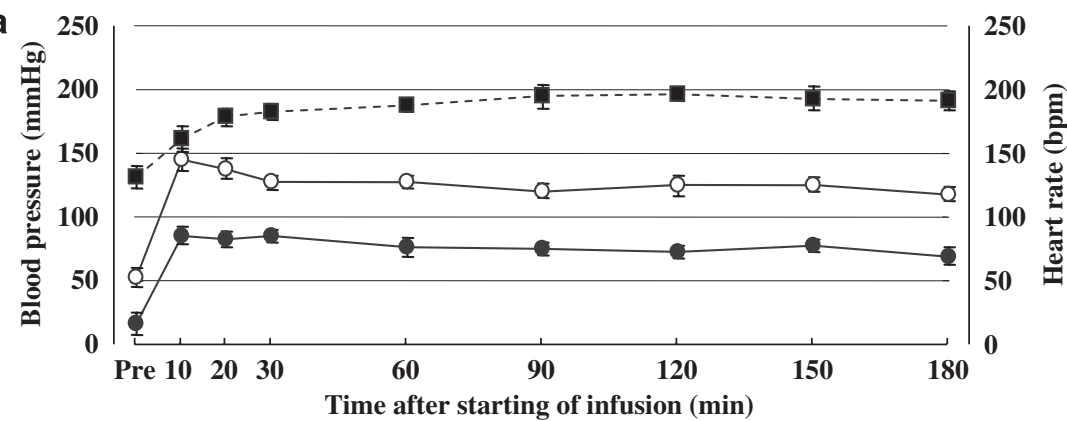

$\multimap-$ SBP $\rightarrow$ DBP - - HR

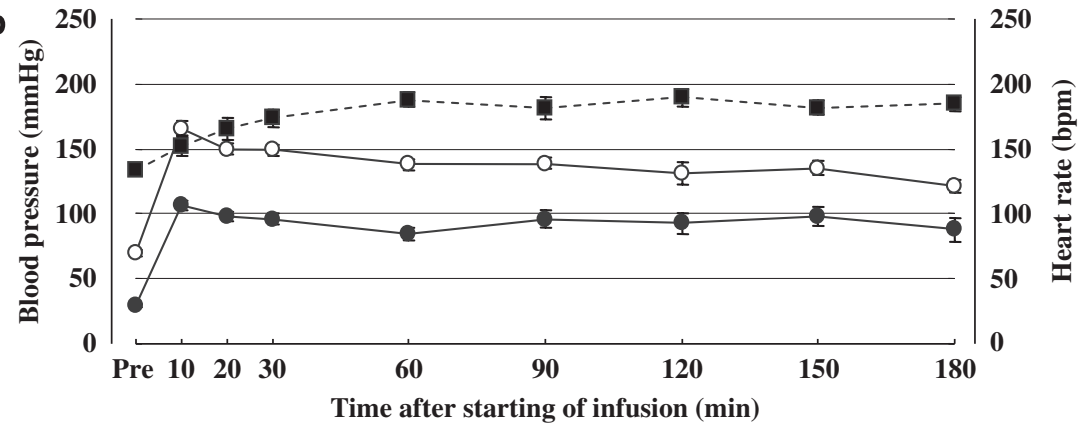

Figure 2 Changes in blood pressure (systolic and diastolic) and heart rate during the first (a) and second (b) epinephrine infusions. Each point represents the mean \pm s.e.m. from 16 animals.

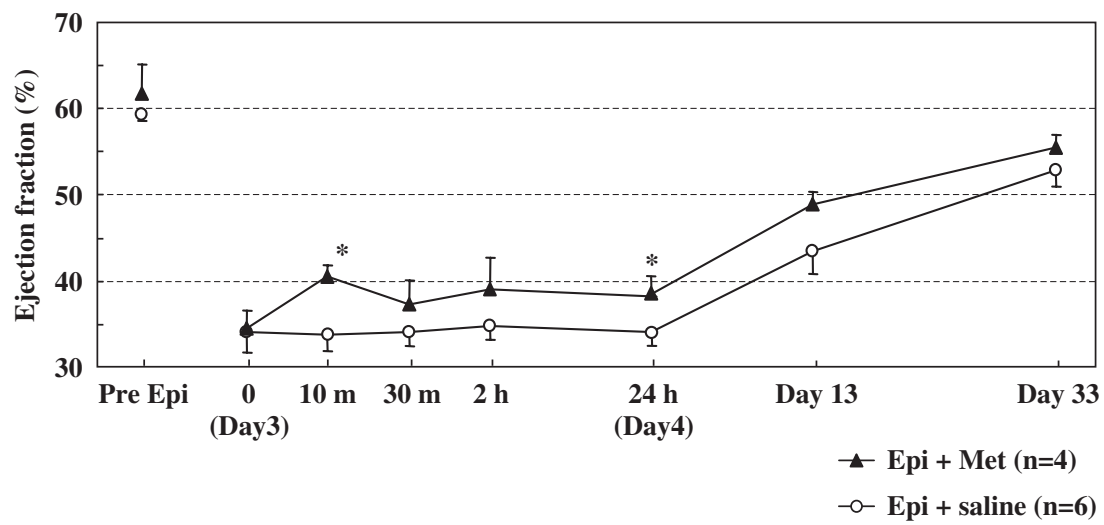

Figure 3 Time course of the ejection fraction after administration of metoprolol. 'Pre' represents values on day 3 (first epinephrine-infused day). Days 13 and 33 represent 10 and 30 days, respectively, after treatment with metoprolol $(\mathbf{\Lambda})$ or saline $(O)$. Each point represents the mean \pm s.e.m. ( $n=4-6)$.

\section{Effects of metoprolol on myocytolysis}

In the second set of experiments, after echocardiography, left ventricles were excised and a part embedded in paraffin at $24 \mathrm{~h}$ after metoprolol infusion. As reproducible results, metoprolol significantly improved the decrease in EF by epinephrine (Figure 4a). Next, to elucidate myocytolysis in the monkey heart, Luxol fast blue staining was performed. Increased myocytolysis was observed in the apical region of the epinephrine-infused heart. Metoprolol diminished cardiomyocytolysis caused by epinephrine (Figure $4 b$ ).

\section{Effects of metoprolol on gene expression in the acute} cardiomyopathy model

To explain the effect of epinephrine and metoprolol on gene expression in each portion of the heart, quantitative real-time reverse
transcriptase-PCR was performed using RNA samples isolated from the apical or basal portions of the left ventricle of each group. We investigated the expression levels involved in heart failure-, calcium signaling-, renin-angiotensin system-, mitochondria- and adrenalinrelated genes.

As shown in Figure 5a, brain natriuretic peptide (BNP)/natriuretic peptide precursor B (NPPB), connective tissue growth factor (CTGF) and osteopontin (OPN) in apical myocardium were remarkably increased by epinephrine. BNP expression was also increased in basal myocardium, but CTGF was not affected by epinephrine. OPN tended to decrease rather in the basal region. The apical CTGF expression level was similar to that in the basal level in control monkeys, whereas apical BNP and OPN levels were 1.6-fold and 2.6-fold higher, respectively, than those in basal regions. The ratio of 

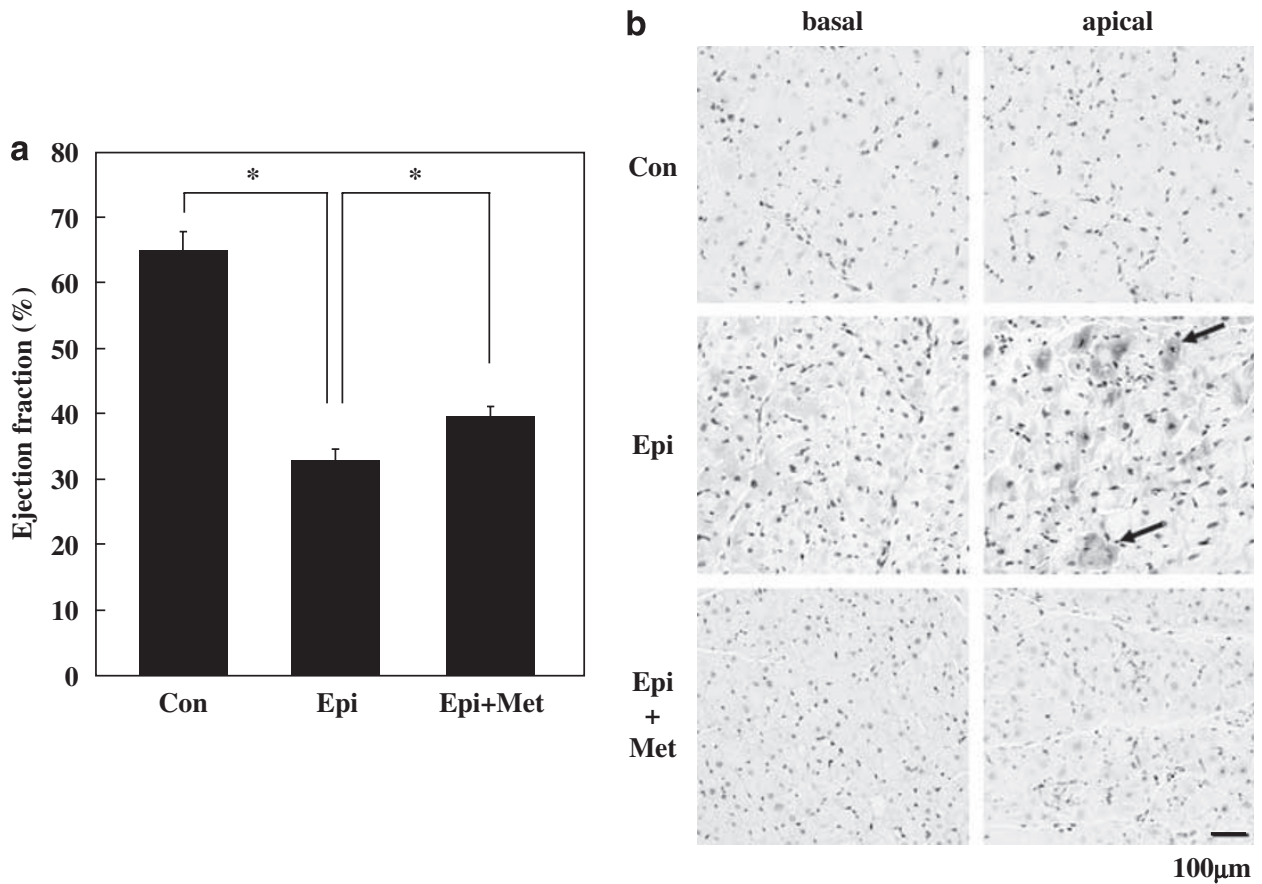

Figure 4 (a) Ejection fraction of control or epinephrine with or without metoprolol by echocardiography. Each bar represents mean \pm s.e.m. ( $n=4-5$ ). ${ }^{*} P<0.05$. (b) Luxol fast blue staining shows myocytolysis in the monkey heart. Con, control; Epi, epinephrine infusion without metoprolol; Epi+Met, epinephrine infusion with metoprolol. Scale bar, $100 \mu \mathrm{m}$. A full colour version of this figure is available at the Hypertension Research journal online.

the apical to basal portions regarding these expressions was significantly increased by epinephrine and tended to be normalized by metoprolol (data not shown).

The mRNA abundance of ryanodine receptor-2 (RYR2) and sarcoendoplasmic reticulum $\mathrm{Ca}^{2+}$-ATPase-2A2 (SERCA2) was significantly decreased by epinephrine injection at the apical portion. Furthermore, the expression of adenylate cyclase-7 (ADCY7) was significantly increased at the same portion by epinephrine. These changes tended to improve by metoprolol treatment. On the other hand, these expression changes at the basal portion were smaller or the opposite (Figure 5b). There was no significant difference in these gene expressions between basal and apical hearts of control monkeys.

We next examined the effect of renin-angiotensin system. At only the apical portion, were angiotensinogen (AGT) and angiotensin II receptor type-2 (AGTR2) significantly upregulated, whereas angiotensin II receptor type-1 (AGTR1) was downregulated by epinephrine (Figure $5 \mathrm{c}$ ). These changes were not much improved by metoprolol.

Mitochondria-related genes such as peroxisome proliferator-activated receptor- $\gamma$ co-activator- $1 \alpha$ (PGC- $1 \alpha)$, cytochrome $c$ (CYCS) and transcription factor A mitochondrial (TFAM) at the apical portion were significantly reduced by epinephrine, and some of them were improved with metoprolol treatment (Figure 5d). Apical PGC- $1 \alpha$ level was 2.4-fold higher than that of the basal in control hearts.

Finally, we checked the expressions of adorenoceptor-related genes such as adrenergic receptor, $\beta 2$ (ADRB2), adrenergic receptor, $\alpha 2 \mathrm{c}$ (ADRA2C) and monoamine oxidase A (MAOA) (Figure 5e). These genes were not significantly changed by epinephrine infusion. In control hearts, apical ADBR2 level was 1.5-fold higher than that of the basal. On the other hand, apical MAOA was half in comparison with that of the basal.

\section{DISCUSSION}

In this study, echocardiographic measurements revealed that repeated intravenous infusion with epinephrine in cynomolgus monkeys induced LV dysfunction with apical ballooning and wall motion abnormalities. To our knowledge, this is the first animal model showing that repetitive injection of epinephrine overdose in a nonhuman primate produced acute and reversible LV dysfunction, namely, acute cardiomyopathy, which mimics that of takotsubo cardiomyopathy in clinical cases. A form of LV systolic dysfunction is characterized by extensive apical akinesia with normal or hypercontractile baseline segments. Furthermore, EF fell below $40 \%$ in all the cases. The dysfunction in this model exhibits both apical akinesis and basal hypokinesis in the left ventricle in the acute phase, and normalizes within 30 days after treatment with $\beta$-blockers or saline. In other words, this LV dysfunction model was acute and reversible cardiac disease. With regard to patients with takotsubo cardiomyopathy, the following were reported: ${ }^{7-9,27,28}$ a reversible wall motion abnormality, transient ST segment abnormalities on the ECG, minimal evidence of epicardial coronary artery stenosis, vasospasm, disturbance of microcirculation, physical or emotional stress as a triggering factor and minimal pathological evidence of acute myocarditis. Earlier research has pointed to the direct toxic effect of catecholamine as a possible cause of these cardiac diseases. The fact that takotsubo cardiomyopathy is frequently preceded by physical or emotional stress implies that activation of the sympathetic nervous system may sometimes be involved in the pathology of this disease. ${ }^{5,29}$ These clinical features of takotsubo cardiomyopathy are closely similar to our model. In this study, we measured only ECG by lead II and showed ECG changes such as an increased $\mathrm{T}$ wave in the early stages after starting epinephrine infusion, an elevated ST segment with a hyper act T wave, an atrioventricular block and premature ventricular contraction, VT 
and polymorphic VT and ventricular fibrillation (Figure 1). In our results, VT and polymorphic VT, which are two of the most malignant forms of ventricular arrhythmias, were observed in some cases unlike clinical reports of takotsubo cardiomyopathy. Sumitomo et al. ${ }^{30}$ showed that catecholamine infusion induces polymorphic VT, which leads to sudden death. Actually, some cynomolgus monkeys died
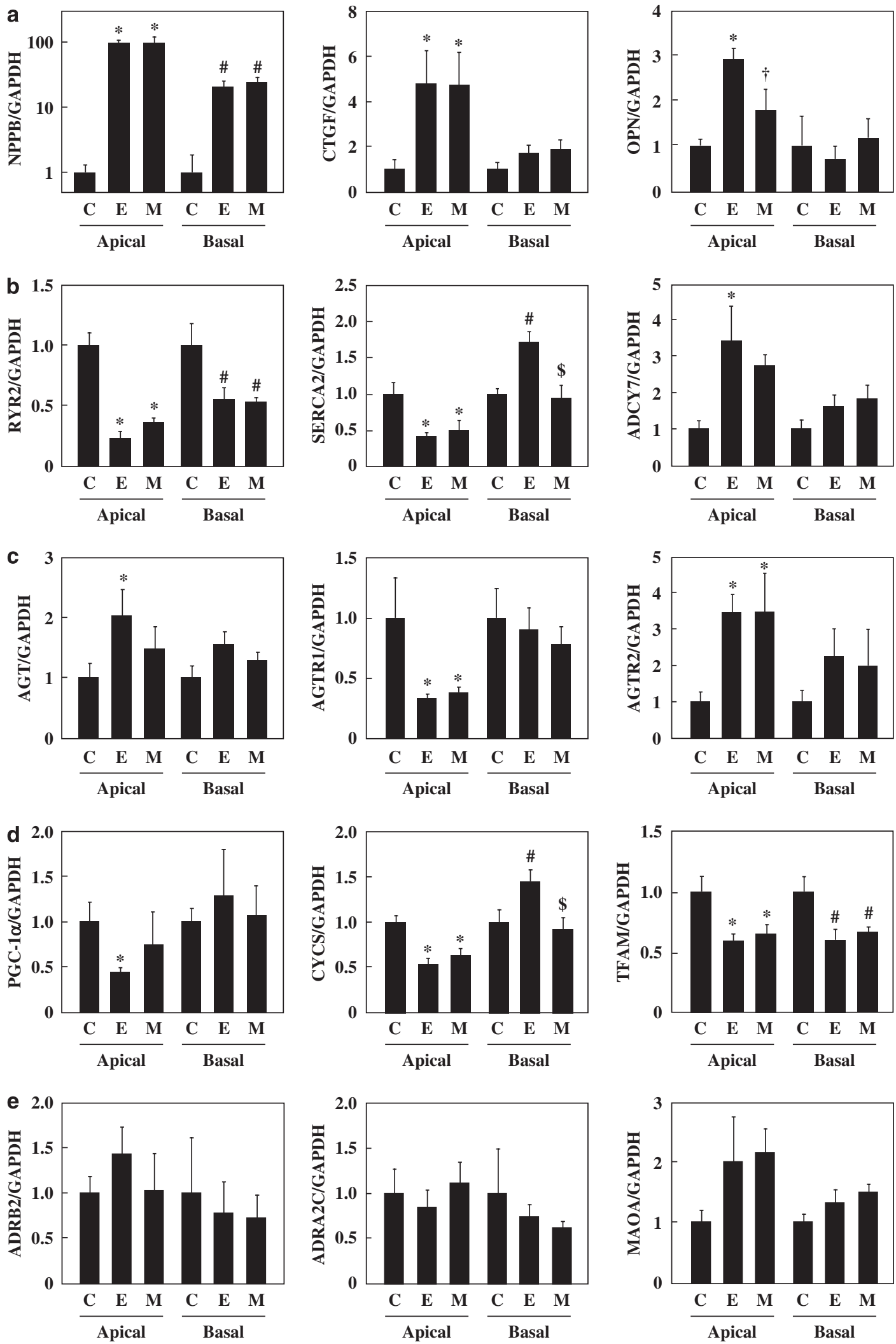
suddenly during or shortly after the first or second epinephrine infusion. Some animals have been used as experimental models of heart failure using excessive dosing of catecholamine. Two-week subcutaneous epinephrine at $7.5 \mu \mathrm{g} \mathrm{kg}^{-1} \mathrm{~min}^{-1}$ infusion to a rat resulted in cardiac injury such as left and right ventricle ischemic lesion and fibrosis. ${ }^{20}$ Three repetitive applications (at 16-day intervals) of high-dose epinephrine $\left(4-5 \mu \mathrm{g} \mathrm{kg}^{-1} \mathrm{~min}^{-1}\right)$ for $60 \mathrm{~min}$ induced progressive LV dilatation and hypertrophy with a depressed LV systolic function. ${ }^{21}$ Excess norepinephrine $\left(4 \mu \mathrm{g} \mathrm{kg}^{-1} \mathrm{~min}^{-1}\right)$ for $90 \mathrm{~min}$ increased LV wall stress. ${ }^{22}$ Similar to these, earlier high-dose catecholamine infusion models are only used to investigate the mechanism of chronic or acute heart failure. Furthermore, impaired cardiac performance in many animal models is irreversible. Therefore, we conclude that this primate cardiac disease model is similar to the model presenting takotsubo cardiomyopathy, although further studies are needed to explain why mammals, with the exception of primates, do not raise takotsubo-like cardiomyopathy by excess catecholamine.

The mechanism underlying the association between takotsubo cardiomyopathy and sympathetic stimulation is still unknown. Wittstein et al..$^{9}$ suggested that the cause of myocardial stunning (takotsubo cardiomyopathy) from sudden emotional stress was because of ischemia resulting from epicardial coronary arterial spasm induced by an increased sympathetic tone from mental stress. Furthermore, electrocardiographic findings such as ST-segment elevation have often been presented in support of this conclusion. Kono et al. ${ }^{31}$ reported that clinical features in transient LV apical ballooning after subarachnoid hemorrhage included increased local norepinephrine release in the heart, and was mediated by the direct toxic effect of norepinephrine. However, the reason for contractile abnormalities of the apex and midportion of the left ventricle with relative sparing of the basal segment still remains unclear.

As a part of the clinical treatment of takotsubo cardiomyopathy, $\beta$-blocker, ${ }^{8,28,32}$ nitroglycerine, ${ }^{8,33,34}$ verapamil, $^{33}$ aspirin $^{8,32}$ and heparin ${ }^{8,33}$ were used. Several investigators ${ }^{35,36}$ reported that propranolol, a $\beta$-blocker, may be very effective in patients who showed a significant intraventricular pressure gradient because of the activation of the sympathetic nerve. The efficacy of $\beta$-blockers may be attributed to the improvement of $\beta$-adrenergic signaling and to protection from catecholamine myocyte toxicity in the heart because of a severe increase in plasma catecholamine and the activation of the sympathetic nerve. In our results, metoprolol rapidly improved the decreased contractile force of the left ventricle in spite of the single dose (Figures 3 and 4 a). These results are consistent with the analysis of myocytolysis by Luxol fast blue staining (Figure $4 \mathrm{~b}$ ). Marechaux et al. ${ }^{37}$ reported on the case of a woman presenting with takotsubo-like cardiomyopathy, subarachnoid hemorrhage and brain death. Histological analysis of the heart confirmed the absence of myocardial infarction and revealed only sparse foci of myocyte necrosis with contraction bands in the akinetic areas. In this assay, no significant change was observed among the three groups with regard to myo- cytolysis at the basal portion. Epinephrine induced myocytolysis randomly at the apical portion, which was ameliorated with metoprolol. Thus, a change in myocytolysis may contribute to a significant improvement of the LV function.

The mechanism whereby epinephrine caused takotsubo-like LV dysfunction and the manner in which $\beta$-blockers ameliorated LV dysfunction in this study remain unclear. Therefore, we investigated the effect of epinephrine and metoprolol in several gene expression levels at the apical and basal portions. CTGF and OPN, as well as ANP and BNP/NPPB are common diagnostic markers of heart failure. ${ }^{38,39}$ In this study, epinephrine significantly increased CTGF and OPN expressions at the apical portion, whereas these expressions were not changed by epinephrine at the basal portion (Figure 4a), indicating that epinephrine genes at the apical portion may be more susceptible than those at the basal. Metoprolol reduced the OPN expression, but did not affect CTGF. Calcium malfunction plays a central role in heart failure. $\beta$-adrenoceptors increase intracellular cAMP levels and decrease the activity of protein kinase A (PKA) by ADCY7. ${ }^{40}$ The downstream effect of reduced PKA activity includes a reversal of desensitization and internalization of $\beta$-adrenoceptors. Renin-angiotensin system plays a crucial role in the development of cardiac hypertrophy and heart failure under excessive $\beta$-adrenergic stimulation. ${ }^{41}$ In addition, $\beta$-adrenoceptor blockers may improve energy balance in a failing heart. Here, we investigated the effect of epinephrine and metoprolol on calcium signaling-, renin-angiotensin system- and mitochondriarelated genes. Predictably, epinephrine significantly decreased RYR2 and SERCA2 expressions at the apical portion, and increased the ADCY7 expression. These changes tended to improve with metoprolol. To compensate for the apical portion, SERCA2 expression at the basal portion may be increased by epinephrine. At the apical portion, AGTR1 mRNA was significantly reduced by epinephrine, whereas AGTR2 was remarkably increased. Earlier data showed that LV AT1 and AT2 mRNAs were decreased in human heart failure, ${ }^{42,43}$ suggesting that our study may be suitable as a heart failure model. Expressions of PGC- $1 \alpha$, CYCS and TFAM, which are mitochondria-related genes, were significantly repressed by epinephrine at the apical portion. These data show that excess epinephrine reduces metabolic energy because deterioration of these genes precipitated mitochondrial abnormalities, myocyte apoptosis and heart failure. ${ }^{44}$ Taken together with the earlier data showing that canine heart has a higher concentration of $\beta$-adrenoceptors in the apical myocardium, with the concentration gradient decreasing from apex to base, ${ }^{45}$ the apex might be more sensitive than the basal myocardium to circulating catecholamines.

In conclusion, repeated intravenous infusion of epinephrine overdose in anesthetized cynomolgus monkeys induced acute cardiomyopathy, which is characterized by progressive left ventricle and depressed systolic function, with severe hypokinesis in the apical region and hyperkinesis in the basal region. Metoprolol improved the decreased EF. Furthermore, epinephrine-induced changes of heart

Figure 5 Effects of epinephrine and metoprolol on expression of the heart failure-related genes (a), calcium signaling-related genes (b), renin-angiotensin system-related genes (c), mitochondria-related genes (d) and adrenalin-related genes (e) at the apical or basal portions of the heart. Ventricular transcript levels were determined by real-time quantitative reverse transcriptase-PCR, and normalized to glyceraldehyde-3-phosphate dehydrogenase (GAPDH). NPPB, natriuretic peptide precursor type B (BNP); CTGF, connective tissue growth factor; OPN, osteopontin; RYR2, ryanodine receptor-2; SERCA2, sarcoendoplasmic reticulum $\mathrm{Ca}^{2+}$-ATPase 2A2; ADCY7, adenylate cyclase-7; AGT, angiotensinogen; AGTR1, angiotensin II receptor type 1; AGTR2, angiotensin II receptor type 2; PGC-1 $\alpha$, peroxisome proliferator-activated receptor- $\gamma$ co-activator-1 $\alpha$; CYCS, cytochrome $c$; TFAM, transcription factor A mitochondrial; ADBR2, adrenergic receptor, $\beta 2$; ADRA2C, adrenergic receptor, $\alpha 2 c$; MAOA, monoamine oxidase A; C, control; E, epinephrine infusion without metoprolol; $\mathrm{M}$, epinephrine infusion with metoprolol. The mean value of control at the apical or basal portions of the ventricle is represented as 1 . Each bar represents mean \pm s.e.m. ( $n=4-5)$. ${ }^{\star} P<0.05$ vs. $\mathrm{C}$ (apical), ${ }^{\dagger} P<0.05$ vs. $\mathrm{E}$ (apical), ${ }^{\#} P<0.05$ vs. $\mathrm{C}$ (basal), $\$ P<0.05$ vs. $\mathrm{E}$ (basal). 
failure-related gene expressions at the apical region were similar to those in human heart failure. These results indicate that this model is valuable in understanding the pathogenesis of takotsubo cardiomyopathy associated with a hypersympathomimetic condition in a relevant non-human primate model. Moreover, $\beta$-blockers may improve cardiac contractile dysfunction in subjects with takotsubo cardiomyopathy.

\section{ACKNOWLEDGEMENTS}

We thank Azusa Inagaki and Masako Tanaka for their technical assistance. This work was supported in part by Grant-in-Aid for Scientific Research from the Ministry of Health, Labour and Welfare of Japan (to Hiroshi Iwao), and from the Ministry of Education, Culture, Sports, Science and Technology of Japan (20590257 to Yasukatsu Izumi).

1 Ako J, Sudhir K, Farouque HM, Honda Y, Fitzgerald PJ. Transient left ventricular dysfunction under severe stress: brain-heart relationship revisited. Am J Med 2006; 119: 10-17.

2 Dec GW. Recognition of the apical ballooning syndrome in the United States. Circulation 2005; 111: 388-390.

3 Girod JP, Messerli AW, Zidar F, Tang WH, Brener SJ. Images in cardiovascular medicine. Tako-tsubo-like transient left ventricular dysfunction. Circulation 2003; 107: e120-e121.

4 Kurisu S, Sato H, Kawagoe T, Ishihara M, Shimatani Y, Nishioka K, Kono Y, Umemura T, Nakamura S. Tako-tsubo-like left ventricular dysfunction with ST-segment elevation: a novel cardiac syndrome mimicking acute myocardial infarction. Am Heart J 2002; 143 : 448-455.

5 Lyon AR, Rees PS, Prasad S, Poole-Wilson PA, Harding SE. Stress (Takotsubo) cardiomyopathy-a novel pathophysiological hypothesis to explain catecholamineinduced acute myocardial stunning. Nat Clin Pract Cardiovasc Med 2008; 5: 22-29.

6 Tsuchihashi K, Ueshima K, Uchida T, Oh-mura N, Kimura K, Owa M, Yoshiyama M, Miyazaki S, Haze K, Ogawa H, Honda T, Hase M, Kai R, Morii I, Angina PectorisMyocardial Infarction Investigations in Japan. Transient left ventricular apical ballooning without coronary artery stenosis: a novel heart syndrome mimicking acute myocardial infarction. Angina Pectoris-Myocardial Infarction Investigations in Japan. J Am Coll Cardiol 2001; 38: 11-18.

7 Merli E, Sutcliffe S, Gori M, Sutherland GG. Tako-Tsubo cardiomyopathy: new insights into the possible underlying pathophysiology. Eur J Echocardiogr 2006; 7: 53-61.

8 Sharkey SW, Lesser JR, Zenovich AG, Maron MS, Lindberg J, Longe TF, Maron BJ. Acute and reversible cardiomyopathy provoked by stress in women from the United States. Circulation 2005; 111: 472-479.

9 Wittstein IS, Thiemann DR, Lima JA, Baughman KL, Schulman SP, Gerstenblith G, Wu KC, Rade JJ, Bivalacqua TJ, Champion HC. Neurohumoral features of myocardial stunning due to sudden emotional stress. N Engl J Med 2005; 352: 539-548.

10 Watanabe H, Kodama M, Okura Y, Aizawa Y, Tanabe N, Chinushi M, Nakamura Y, Nagai T, Sato M, Okabe M. Impact of earthquakes on Takotsubo cardiomyopathy. JAMA 2005; 294: 305-307.

11 Budhwani N, Bonaparte KL, Cuyjet AB, Saric M. Severe reversible left ventricular systolic and diastolic dysfunction due to accidental iatrogenic epinephrine overdose. Rev Cardiovasc Med 2004; 5: 130-133.

12 Sato Y, Tanaka M, Nishikawa T. Reversible catecholamine-induced cardiomyopathy by subcutaneous injections of epinephrine solution in an anesthetized patient. Anesthesiology 2000; 92: 615-619.

13 de Souza F, Altenburg Odebrecht Curi Gismondi R, Henriques Cunha Neto S, de Mattos MA. Tako-tsubo-like cardiomyopathy and extra-adrenal pheochromocytoma: case report and literature review. Clin Res Cardiol 2008; 97: 397-401.

14 Spes C, Knape A, Mudra H. Recurrent tako-tsubo-like left ventricular dysfunction (apical ballooning) in a patient with pheochromocytoma - a case report. Clin Res Cardiol 2006; 95: 307-311.

15 Ionescu A. Subaortic dynamic obstruction: a contributing factor to haemodynamic instability in tako-tsubo syndrome? Eur J Echocardiogr 2008; 9: 384-385.

16 Dhoble A, Abdelmoneim SS, Bernier M, Oh JK, Mulvagh SL. Transient left ventricular apical ballooning and exercise induced hypertension during treadmill exercise testing: is there a common hypersympathetic mechanism? Cardiovasc Ultrasound 2008; 6: 37.

17 Fripp RR, Lee JC, Downing SE. Inotropic responsiveness of the heart in catecholamine cardiomyopathy. Am Heart J 1981; 101: 17-21.

18 Jiang JP, Downing SE. Catecholamine cardiomyopathy: review and analysis of pathogenetic mechanisms. Yale J Biol Med 1990; 63: 581-591.

19 Simons M, Downing SE. Coronary vasoconstriction and catecholamine cardiomyopathy. Am Heart J 1985; 109: 297-304.

20 Deisher TA, Narita H, Zera P, Ginsburg R, Bristow MR, Billingham ME, Fowler MB, Hoffman BB. Protective effect of clentiazem against epinephrine-induced cardiac injury in rats. J Pharmacol Exp Ther 1993; 266: 262-269.

21 Muders F, Friedrich E, Luchner A, Pfeifer M, Ickenstein G, Hamelbeck B, Riegger GA, Elsner D. Hemodynamic changes and neurohumoral regulation during development of congestive heart failure in a model of epinephrine-induced cardiomyopathy in conscious rabbits. J Card Fail 1999; 5: 109-116.

22 Jolly SR, Reeves WC, Mozingo S, Mehta P, Gilliland MG, Wilson E, Movahed A. Effect of diltiazem on norepinephrine-induced acute left ventricular dysfunction. Int J Cardiol 1992; 36: 31-40.

23 Khorchid A, Fragoso G, Shore G, Almazan G. Catecholamine-induced oligodendrocyte cell death in culture is developmentally regulated and involves free radical generation and differential activation of caspase-3. Glia 2002; 40: 283-299.

24 Tsusaki H, Yonamine H, Tamai A, Shimomoto M, Iwao H, Nagata R, Kito G. Evaluation of cardiac function in primates using real-time three-dimensional echocardiography as applications to safety assessment. J Pharmacol Toxicol Methods 2005; 52: 182-187.

25 Tsusaki H, Yonamine H, Tamai A, Shimomoto M, Kuwano K, Iwao H, Nagata R, Kito G. Left ventricular volume and function in cynomolgus monkeys using real-time threedimensional echocardiography. J Med Primatol 2007; 36: 39-46.

26 Li J, Leschka S, Rutschow S, Schwimmbeck PL, Husmann L, Noutsias M, Westermann D, Poller W, Zeichhardt H, Klingel K, Tschope C, Schultheiss HP, Pauschinger M. Immunomodulation by interleukin-4 suppresses matrix metalloproteinases and improves cardiac function in murine myocarditis. Eur J Pharmacol 2007; 554: 60-68.

27 Abe Y, Kondo M, Matsuoka R, Araki M, Dohyama K, Tanio H. Assessment of clinical features in transient left ventricular apical ballooning. J Am Coll Cardiol 2003; 41: 737-742.

28 Metzl MD, Altman EJ, Spevack DM, Doddamani S, Travin MI, Ostfeld RJ. A case of Takotsubo cardiomyopathy mimicking an acute coronary syndrome. Nat Clin Pract Cardiovasc Med 2006; 3: 53-56; quiz 57.

29 Prasad A, Lerman A, Rihal CS. Apical ballooning syndrome (Tako-Tsubo or stress cardiomyopathy): a mimic of acute myocardial infarction. Am Heart J 2008; 155: 408-417.

30 Sumitomo N, Harada K, Nagashima M, Yasuda T, Nakamura Y, Aragaki Y, Saito A, Kurosaki K, Jouo K, Koujiro M, Konishi S, Matsuoka S, Oono T, Hayakawa S, Miura M, Ushinohama H, Shibata T, Niimura I. Catecholaminergic polymorphic ventricular tachycardia: electrocardiographic characteristics and optimal therapeutic strategies to prevent sudden death. Heart 2003; 89: 66-70.

31 Kono T, Morita H, Kuroiwa T, Onaka H, Takatsuka H, Fujiwara A. Left ventricular wall motion abnormalities in patients with subarachnoid hemorrhage: neurogenic stunned myocardium. J Am Coll Cardiol 1994; 24: 636-640.

32 Connelly KA, Maclsaac Al, Jelinek VM. Stress, myocardial infarction, and the 'takotsubo' phenomenon. Heart 2004; 90: e52.

33 Meaudre E, Barbou F, Sallaberry M, Cantais E, Petit D, Palmier B. Rapid reversal of global left ventricular dysfunction after accidental injection of $0.75 \mathrm{mg}$ epinephrine in a 20-year-old patient. Acta Anaesthesiol Scand 2004; 48: 914-916.

34 Kurisu S, Inoue I, Kawagoe T, Ishihara M, Shimatani Y, Nakama Y, Kagawa E. Pressure tracings in obstructive Tako-Tsubo cardiomyopathy. Eur J Heart Fail 2007; 9: 317-319.

35 Kyuma M, Tsuchihashi K, Shinshi Y, Hase M, Nakata T, Ooiwa H, Abiru M, Hikita N, Adachi T, Shoji T, Fujise Y, Shimamoto K. Effect of intravenous propranolol on left ventricular apical ballooning without coronary artery stenosis (ampulla cardiomyopathy): three cases. Circ J 2002; 66: 1181-1184

36 Yoshioka T, Hashimoto A, Tsuchihashi K, Nagao K, Kyuma M, Ooiwa H, Nozawa A Shimoshige S, Eguchi M, Wakabayashi T, Yuda S, Hase M, Nakata T, Shimamoto K. Clinical implications of midventricular obstruction and intravenous propranolol use in transient left ventricular apical ballooning (Tako-tsubo cardiomyopathy). Am Heart $J$ 2008; 155: 526.e1-526.e7.

37 Marechaux S, Fornes P, Petit S, Poisson C, Thevenin D, Le Tourneau T, Asseman P, Bruneval P, Ennezat PV. Pathology of inverted Takotsubo cardiomyopathy. Cardiovasc Pathol 2008; 17: 241-243.

38 Kramer F, Sandner P, Klein M, Krahn T. Plasma concentrations of matrix metalloproteinase-2, tissue inhibitor of metalloproteinase-1 and osteopontin reflect severity of heart failure in DOCA-salt hypertensive rat. Biomarkers 2008; 13: 270-281.

39 Koitabashi N, Arai M, Niwano K, Watanabe A, Endoh M, Suguta M, Yokoyama T, Tada H, Toyama T, Adachi H, Naito S, Oshima S, Nishida T, Kubota S, Takigawa M, Kurabayashi M. Plasma connective tissue growth factor is a novel potential biomarker of cardiac dysfunction in patients with chronic heart failure. Eur J Heart Fail 2008; 10: 373-379.

40 Wang X, Dhalla NS. Modification of beta-adrenoceptor signal transduction pathway by genetic manipulation and heart failure. Mol Cell Biochem 2000; 214: 131-155.

41 Zhang GX, Ohmori K, Nagai Y, Fujisawa Y, Nishiyama A, Abe Y, Kimura S. Role of AT1 receptor in isoproterenol-induced cardiac hypertrophy and oxidative stress in mice. J Mol Cell Cardiol 2007; 42: 804-811.

42 Regitz-Zagrosek V, Fielitz J, Dreysse R, Hildebrandt AG, Fleck E. Angiotensin receptor type 1 mRNA in human right ventricular endomyocardial biopsies: downregulation in heart failure. Cardiovasc Res 1997; 35: 99-105.

43 Tsutsumi Y, Matsubara H, Ohkubo N, Mori Y, Nozawa Y, Murasawa S, Kijima K, Maruyama K, Masaki H, Moriguchi Y, Shibasaki Y, Kamihata H, Inada M, Iwasaka T. Angiotensin II type 2 receptor is upregulated in human heart with interstitial fibrosis, and cardiac fibroblasts are the major cell type for its expression. Circ Res 1998; 83: 1035-1046.

44 Sano M, Izumi Y, Helenius K, Asakura M, Rossi DJ, Xie M, Taffet G, Hu L, Pautler RG, Wilson CR, Boudina S, Abel ED, Taegtmeyer H, Scaglia F, Graham BH, Kralli A, Shimizu N, Tanaka H, Mäkelä TP, Schneider MD. Menage-a-trois 1 is critical for the transcriptional function of PPAR gamma coactivator 1. Cell Metab 2007; 5: 129-142.

45 Mori H, Ishikawa S, Kojima S, Hayashi J, Watanabe Y, Hoffman JI, Okino H. Increased responsiveness of left ventricular apical myocardium to adrenergic stimuli. Cardiovasc Res 1993; 27: 192-198. 